\title{
AN ASSESSMENT OF LEPORID RESEARCH AND LANDSCAPE ECOLOGY METRICS IN A EUROPEAN LANDSCAPE
}

\author{
KELSEY GILCREASE
}

South Dakota School of Mines and Technology, 501 E. St. Joseph Street, Rapid City, South Dakota 57701, PH: 605-394-6020, email: Kelsey.gilcrease@sdsmt.edu

Received: $9^{\text {th }}$ September 2012, Accepted: $8^{\text {th }}$ March 2013

\begin{abstract}
Leporids play a dynamic role in the ecosystem and assessments must be undertaken in order to improve research efforts and methods. Landscape ecology metrics are used to quantify components of leporid habitat such as vegetation structure, vegetation cover, habitat type, and fragmentation; however, the degree to which the metrics are utilized in leporid research is relatively unknown. This paper assessed fifty-three published, peer reviewed papers on leporids from various European countries on where the study was done, the species of leporid that was studied, the content of the study (i.e. what the paper focused on), the length of the study, the size of the study area, and the method of study. The quantified landscape metrics within these papers were assessed. This study found that most of the studies occurred in Spain, the European rabbit and European hare were the most studied leporids, many papers were concerned with habitat relationships, many of the studies were conducted in a year or less, many papers utilized pellet surveys and trapping, and the most common landscape metric utilized was habitat type. This survey of research on leporids highlights that there is a lack of utilizing landscape structure and function metrics such as slope, fragmentation, and edge effect. These are important variables to help connect structure and function of ecological processes in the context of leporid habitat and landscapes. It is recommended that leporid researchers and landscape planners exchange research findings so that the best planning practices can occur on the ground for the leporids.
\end{abstract}

Keywords: Assessment; Landscape Ecology; Leporids; Ecological Processes.

\section{INTRODUCTION}

Population abundance estimates, habitat requirements, species dispersion, and species interactions are commonly studied subjects in wildlife. Retrospectively assessing these wildlife studies can serve to improve field work and research methods. Leporids (rabbits and hares) are prey species, herbivores, and seed dispersers (Zedler and Black 1992; Dellafiore et al. 2010). Since leporids play a paramount role in the ecosystem, it is important to continually improve leporid study research efforts. A number of studies have been conducted to compare methods for European rabbit (Oryctolagus cuniculus) population size/abundance (e.g. Palomares 2001; Ballinger and Morgan 2006; Marchandeau et al 2006; Barrio et al. 2010), and population growth rates (Caley and 
Morley 2002) to improve leporid population abundance methods. Further, Eberhardt et al. (1963) researched an amalgam of problems in a rabbit population study (i.e. trapping, mortality, frequency of capture, age ratios) with Eastern cottontails (Sylvilagus floridanus). However, little work has been done to assess gaps and to determine what content has been emphasized in leporid research in a region with multiple leporid species.

Spain, Italy, France, Germany, Switzerland, Sweden, Portugal, and England contain a variety of leporid species such as the Mountain hare (Lepus timidus), Italian or Corsican hare (Lepus corsicanus), European rabbit (Oryctolagus cuniculus), European or Brown hare (Lepus europaeus), Broom hare (Lepus castroviejoi), and Iberian hare (Lepus granatensis). These leporids inhabit a variety of climates, altitudes, and biomes. These countries also have a variety of ecosystem types with mountains, wetlands, grasslands, and forests.

Quantifiable landscape ecology metrics such as vegetation structure, edge effects, fragmentation, topography, and land use inform management implications. These metrics inform management implications with regards to patch size and shape requirements, distance from urban structures, or other measures for ecological processes. Noss (1990) separates structure and function metrics such that heterogeneity, connectivity, fragmentation, slope/aspect, and patchiness are components of landscape structure and land use trends, colonization rates, nutrient cycling rates, and disturbance are components of landscape function. These landscape ecology metrics (i.e. vegetation type, topography, edge effects) have been used in leporid studies (e.g. Barrio et al. 2009; Ferreira \& Alves 2009; Petrovan et al. 2011); however, it is uncertain which landscape metrics are utilized the most and the least in leporid studies in a European context. This paper will provide an indication of which landscape metrics are used more and less often in leporid studies within European landscapes, as some metrics may need more or less focus in leporid studies.

The aim of this paper is to assess peer-reviewed studies on leporids conducted in various European countries. The review includes the following components: content of the study, length of study, method of study, size of study area, and the species investigated. I used these data to assess the quantified landscape metrics within each paper. This procedure highlights gaps and determines where the emphasis on research has been placed. This work picks up after Eberhardt et al. (1963) who focused on generalized tribulations that they discovered with population studies of the Eastern cottontail; however, this paper will pick up on generalized issues with multiple leporid species in a region with an emphasis on landscape ecology metrics.

\section{METHODS}

\section{Literature scope and focus}

The review focused on peer reviewed journal articles with rabbits and hares within a Spanish, Italian, French, Swiss, Swedish, German, Portuguese, or English landscape. Papers with regard to meat quality, leporid diet selection, disease, genetics, reproduction of rabbits or hares, leporids in laboratory settings, studies with multiple countries, or studies with multiple species other than rabbits and hares were not considered.

Specific words were typed into ISI Web of Knowledge topic: "rabbit OR hare" title, topic "Spain" OR "Italy" OR "England” OR "Switzerland” OR "Germany" OR "France”, OR "Sweden" OR "Portugal" topic: landscape. Other on-line academic databases were also searched with those words. Only publication years from 2000-2012 were considered.

Microsoft Excel 2007 was used to create the figures. 


\section{RESULTS}

A total of 64 peer-reviewed papers matched the literature scope category. Eleven papers were eliminated because they did not meet the scope of the review for this paper. The 53 papers utilized in the assessment are listed in the references. Most of the papers included research that was conducted in Spain, followed by Italy (Fig. 1).

Fig. 1: The number of leporid papers that matched the literature scope category with respect to the countries where research was undertaken

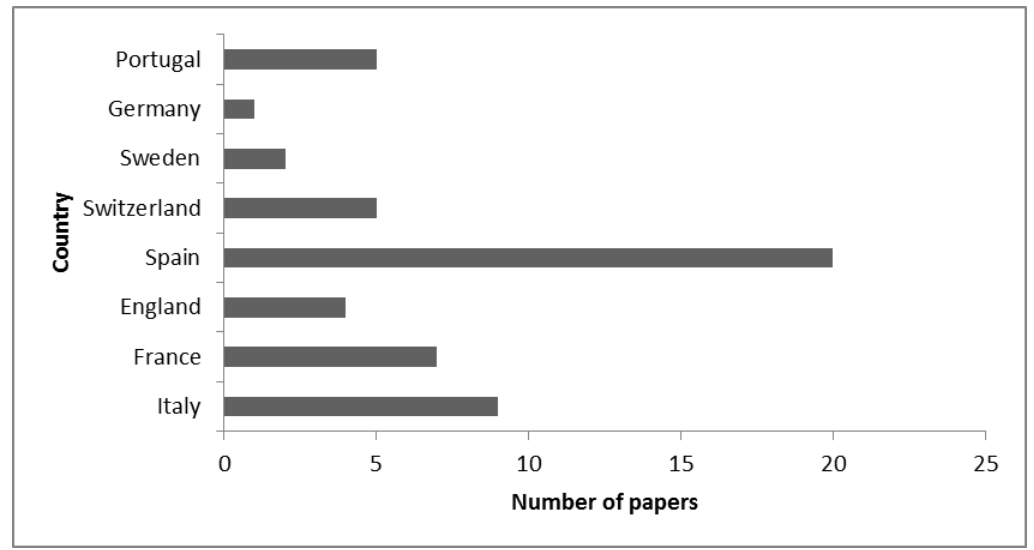

Next, most of the literature focused on the European rabbit and the European hare (Fig. 2). Some papers focused on more than one species.

Fig. 2: The various leporid species researched within the papers

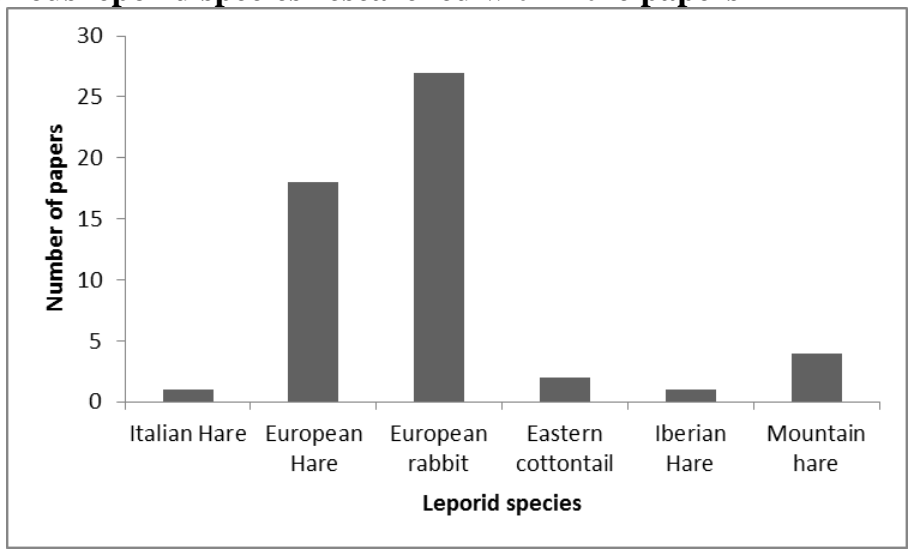

In terms of longevity and size of the studies, $51 \%$ of the studies were conducted in 1 year or less and $34 \%$ of the studies were carried out on less than 1,000 hectares.

A few of the papers $(43 \%)$ used more than one method to study leporids; however, fecal pellet counts, trapping, spotlight surveys, and radio collaring were the most undertaken methods of study (Fig. 3). 
Fig. 3: The method of study utilized in leporid papers

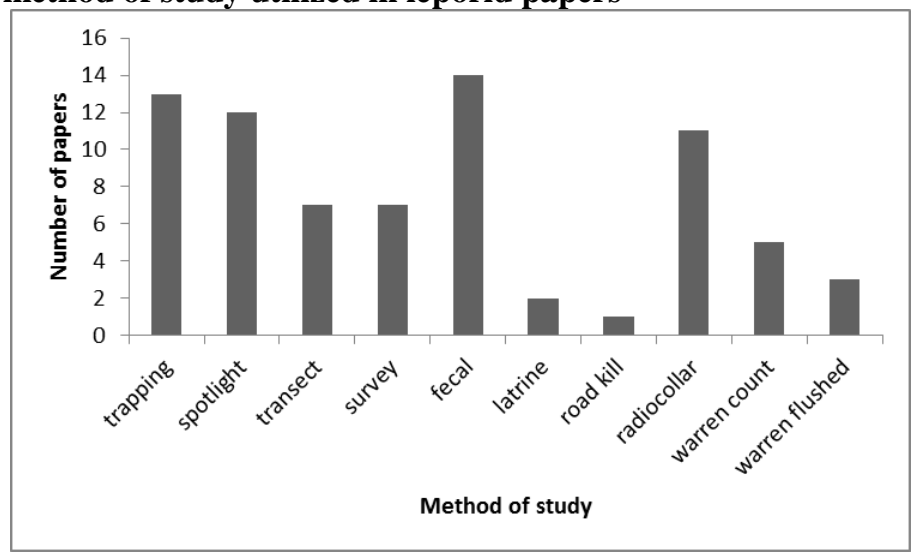

A myriad of quantitative landscape variables were identified within the assessment (Fig. 4). Many of the studies used more than one variable to study leporids (91\%). Habitat type comprised the majority of the variables measured in the study (Fig. 4). In this analysis, it is important to distinguish the difference between vegetation cover and vegetation type, as vegetation cover was considered as protection for the leporid and vegetation type was considered as habitat identification and use.

Fig. 4: Quantitative landscape variables utilized in leporid papers

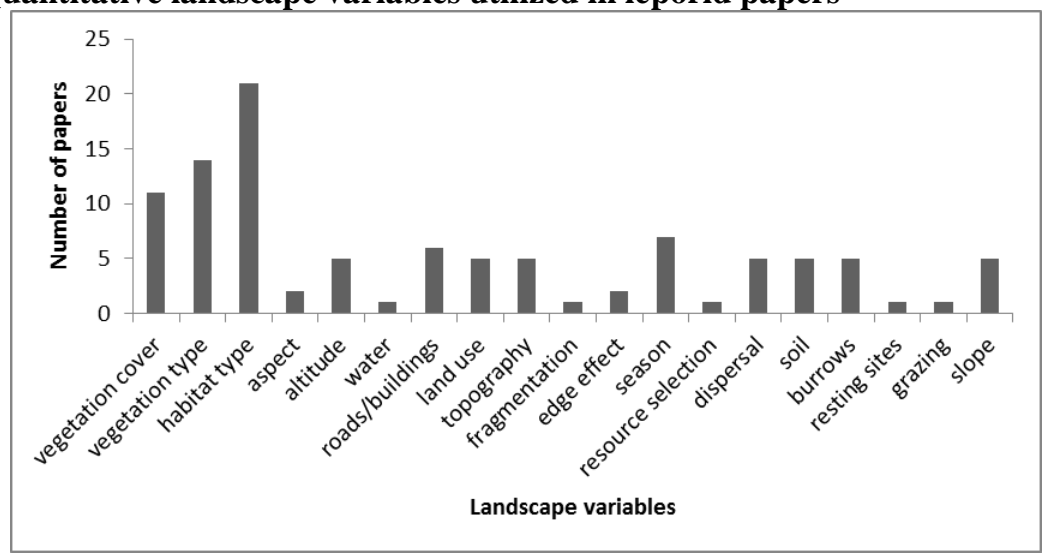

Papers focused on methods for assessing population abundance, distribution and spatial patterns for leporids, habitat relationships, dispersal of leporids, habitat variables, abundance estimates, seed dispersal capabilities from leporids, and leporid home range. A few papers focused on more than one topic; however, the majority of the papers focused on habitat relationships of the leporids (Fig. 5). 


\section{Fig. 5: The topic that the papers focused on with regard to leporid studies}

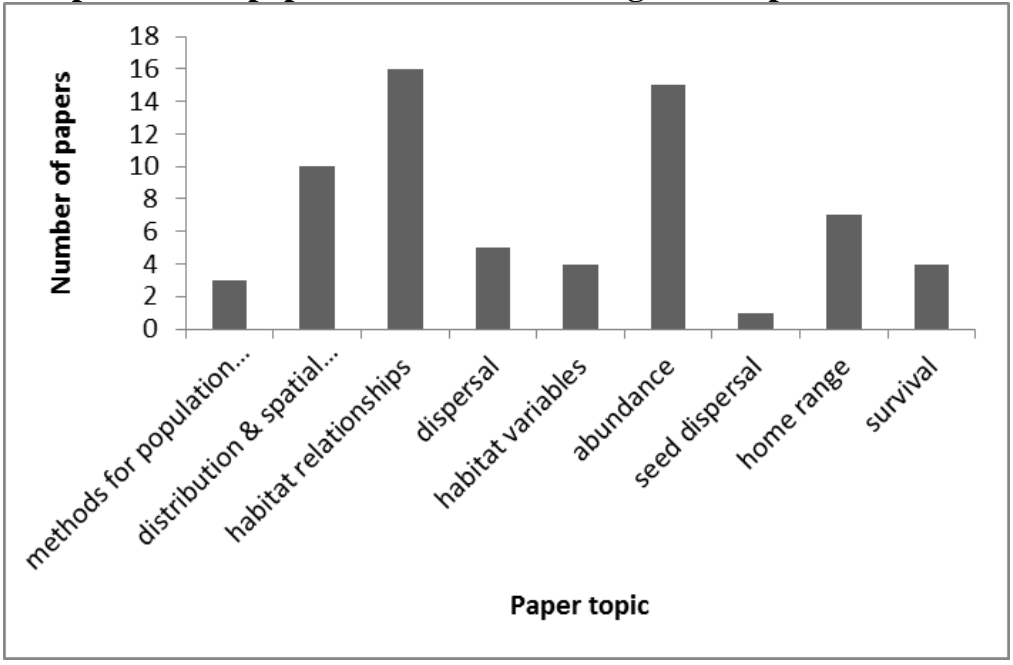

\section{DISCUSSION}

This study suggested that most of the papers focused on the European rabbit and European hare while fewer studies focused on the Iberian hare, Mountain hare, Italian hare, Eastern cottontail, or the Broom hare. Most of the research was located in Spain which contains the European rabbit and hare. Motivations for conducting research on these species may be that these two leporids encompass increasing or decreasing populations. For example, in some places in Europe, the European rabbit is abundant (Petrovan et al. 2011); however, native to the Iberian Peninsula, the status of the European rabbit is of concern in Spain because of the declining population (e.g. Beja et al. 2007; Delibes-Mateos et al. 2009). This decreasing population status is echoed with the brown hare (Gortazar et al. 2007). Martín- López (2009) found that the European rabbit received considerable funding in Spain because it is a prey item for the Iberian lynx (Lynx pardinus) and Spanish Imperial eagle (Aquila adalberti). However, focusing more research on some leporid species and not on others (i.e. Eastern cottontail, Iberian hare, Mountain hare, Italian hare, and Broom hare) could lead to unforeseen conservation dangers such as not knowing the population status, functional relationships, and intraspecific interactions with other leporids. For example, Broom hare habitat is located in between the European hare and Iberian hare habitat (Estanoba et al. 2006) and therefore, the Broom hare could be studied along with the European and/or Iberian hare. It seems likely that the larger the study area, the more leporid species would be involved in the study. In this case, out of five papers that had study areas over 50,000 hectares, two of them studied more than one leporid species.

One of the aims of this paper was to assess the length of the leporid study and the size of the study area. Many of the studies in this paper were one year or less and many papers occurred on less than 10,000 hectares. Conservation decisions benefit from long-term data (Willis et al. 2007) and a limitation that occurs with shorter study periods is that there can be a lack of replication for statistical analysis. However, sometimes studies that are one year or less are inevitable as there could be a lack of funding, the study may need to occur or the opportunity could be lost, and a short term study may be needed to focus on seasonal effects. For example, sometimes it is appropriate to conduct research during a certain 
season (i.e. winter); however, studies could focus on that season each year for a few years. Smaller sized study areas are fine too; however, sometimes the results might not be characteristic for the total population (Johnson 2002).

There are various traditional wildlife survey methods such as roadside counts, spotlight, random sampling, radio-tracking, pellet counts, call counts, trapping, transect methods, aerial surveys, mark-recapture, and mapping. Some studies utilized hunting/bag surveys for leporids. Bag survey information can be useful in terms of identifying leporid hunting trends and quantitatively defining how many leporids were hunted from year to year; however, changes in land use and variation in hunter activity must be considered when conducting this type of study (Hill et al. 2005). In addition, this study found that pellet surveys and trapping were the most commonly used methods in the papers. Pellet surveys are a reliable method to estimate rabbit populations, can be used for long periods of time, and are relatively easy to implement (Palomares 2001, Hill et al. 2005). It must be noted that sometimes leporids deposit more pellets in certain areas (Palomares 2001); therefore, caution must be used with assumptions of statistical tests using fecal pellet counts. For example, swamp rabbits (Sylvilagus aquaticus) often deposit fecal pellets on logs that are decaying (Zollner et al. 1996). Spotlight surveys were also utilized in many of the leporids studies and is also a reliable method (Ballinger and Morgan 2002; Caley and Morely 2002). Marchandeau et al. (2006) and Barrio et al. (2010) point out that rabbit behavior, depending upon weather and lunar phases impinge on the rabbit being above ground therefore, may play a big role in detectability and abundance estimates. The season and time of day may also be important to consider for the study because some rabbits are more active at dusk than they are at midnight (Barrio 2010; Ballinger and Morgan 2002) and detectability may impinge on when rabbits forage (Barrio et al. 2010). As a result, Barrio et al. (2010) suggested that a pilot study could be conducted prior to surveys to identify patterns of activity.

In relation to patterns of activity, a landscape perspective could be taken in order to better understand how leporid habitat functions with ecological processes. Therefore, structure and function of ecological processes and landscapes could be considered in studies (Leitão and Ahern 2002; Lindenmayer et al. 2008) and could use more research (Leitão and Ahern 2002). One of the aims of this paper was to determine which variables were used more or less often in landscape ecology studies dealing with leporids. This study identified that habitat type and habitat relationship topics were the most commonly studied. This finding was echoed by DeStefano (2002) who also found that habitat relationships were a common focus in forest wildlife research and management topics. Habitat relationships may be commonly studied because studies of habitat preferences constitute baseline ecological information (Rosenzweig 1991). Even though habitat studies are important, variables such as topography, edge effect, aspect, connectivity, and slope impinge not only on landscape processes, but on the distribution of species (Catling and Burt 1995; Alexander and Waters 2000). According to Noss' (1990) indicators, the leporid research in this study would have focused more on the compositional components (i.e. habitat type) rather than structural and functional components. A few examples of some selected landscape variables that were identified in published leporid papers include: edge density, land use (Petrovan et al. 2011), topography, elevation, patch area, distance to roads, orchards, hedges (Roedenbeck and Voser 2008), aspect, altitude (Fulgione 2009), slopes, topography and vegetation (Rueda 2008), soil hardness, vegetation structure, elevation, and scrub height (Calvete 2004). It is important that variables such as altitude, aspect, edge effect, and slope continue to grow within leporid research to obtain a more specific understanding of structure and function of ecological processes in leporid landscapes. Leporid research could improve by utilizing 
these landscape structure and function metrics. For example, some of the papers focused on natal dispersal, but did not have much of a focus on landscape factors such as slope/topography, which may impede natal leporid movement. In addition, for studies that considered warren use by leporids, the study could consider soil content, altitude, and erosion. For example, Eldridge and Simpson (2002) found that warren mounds were susceptible to wind and water erosion when the mound does not have vegetation.

Some challenges for the European landscape is that land is more intensively used, farm size is growing (Jongman 2002), the growth of grassland and plantation forestry in marginal regions is increasing (Reger et al. 2007), and landscape homogenization is becoming more prevalent (Reger 2009). Lundström-Gilliéron and Schlaepfer (2003) point out that urbanization, fragmentation, and agriculture intensification occur in the Swiss landscape. It seems likely that these trends and processes will impinge on leporid populations as they adapt to landscape changes. For example, Lundström-Gilliéron and Schlaepfer (2003) found that the brown hare population was impinged by field work, traffic, fragmentation, and prefers forests for refuge amongst other requirements. Therefore, it may be important to utilize the fragmentation, vegetation cover, and urbanization metrics when conducting a study for the brown hare to better understand the link between structure and function of ecological processes in leporid landscape. As far as ecological planning is concerned, Leitão and Ahern (2002) selected nine metrics (e.g. patch richness, patch size, patch shape, edge contrast, and contagion) that are used to define ecological landscape planning and can be used on ecological processes (Leitão and Ahern 2002). In fact, patch size and edge effect metrics were important to consider for the Lower Keys Marsh rabbit (Sylvilagus palustris hefneri) in Florida (Schmidt et al. 2011). Therefore, it is recommended that leporid researchers and landscape planners exchange information so that the best planning practices can occur on the ground for the leporid species.

\section{CONCLUSIONS AND FUTURE RESEARCH}

- There are some caveats that must be considered in this paper, as books were not considered, only peer-reviewed publications in the English language. This paper reviewed papers that came from a few European countries, but did not include all European countries.

- Marchandeau et al. (2006) points out that they completed their study under similar weather conditions and similar lunar phases. These factors may be important to consider for consistency in leporid studies.

- If studies are to be comparable, similar methods should be used so that such comparisons between studies will be able to occur. This study suggested that many of these papers used a variety of methods such as pellet counts, spotlight, trapping and collaring.

- It was recommended to conduct a pilot study (Barrio et al. 2010) so that the behavior, time of day, and/or season of the target leporid can be defined (i.e. to determine if the leporid is more active at night or dusk or during a certain season) (Barrio et al. 2010).

- If able, obtain as much historical population information on the target leporid of study as possible. This may identify historical population trends and/or historical uses of the leporid. A historical approach to leporid studies may facilitate a more holistic perspective on baseline ecological information. 


\section{ACKNOWLEDGEMENTS}

The author would like to thank the anonymous reviewers for their helpful recommendations that improved this manuscript.

\section{REFERENCES}

Alexander, S.M. \& Waters, N.M. (2000). The effects of highway transportation corridors on wildlife: a case study of Banff National Park. Transportation Research Part C: Emerging Technologies 8, 307-320 pp. DOI: 10.1016/S0968-090X(00)00014-0.

Avril, A., Léonard, Y., Letty, J., Péroux, R., Guitton, J-S. \& Pontier, D. (2011). Natal dispersal of European hare in a high-density population. Mammalian Biology 76, pp. 148156. DOI: 10.1016/j.mambio.2010.07.001.

Ballinger, A. \& Morgan, D.G. (2002). Validating two methods for monitoring population size of the European rabbit (Oryctolagus cuniculus). Wildlife Research 29, pp. 431-437. DOI: 10.1071/WR01055.

Barrio, I.C., Bueno, C.G. \& Tortosa, F.S. (2009). Improving predictions of the location and use of warrens in sensitive rabbit populations. Animal Conservation 12, pp. 426-433. DOI: 10.1111/j.1469-1795.2009.00268.x.

Barrio I.C., Acevedo, P. \& Tortosa, F.S. (2010). Assessment of methods for estimating wild rabbit population abundance in agricultural landscapes. European Journal of Wildlife Research 56, pp. 335-340. DOI: 10.1007/s10344-009-0327-7.

Barrio, I.C., Villafuerte, R. \& Tortosa, F.S. (2011). Harbouring pests: rabbit warrens in agricultural landscapes. Wildlife Research 38, pp. 756-761. DOI: http://dx.doi.org/10.1071/ WR11051.

Beja, P., Pais, M. \& Palma, L. (2007). Rabbit Oryctolagus cuniculus habitats in Mediterranean scrubland: the role of scrub structure and composition. Wildlife Biology 13, pp. 28-37. DOI: 10.2981/0909-6396(2007)13[28:ROCHIM]2.0.CO;2.

Bertolino, S., Cordero di Montezemolo, N., Perrone, A. (2011). Daytime habitat selection by introduced Eastern cottontail Sylvilagus floridanus and native European Hare Lepus europaeus in Northern Italy. Zoological Science 28, pp. 414-419. DOI: 10.2108/zsj.28.414.

Bisi, F., Nodari, M., Miguel Dos Santos Oliveira, N., Masseroni, E., Preatoni, D.G., Wauters L.A., Tosi, G. \& Martinoli, A. (2011). Space use patterns of mountain hare (Lepus timidus) on the Alps. European Journal of Wildlife Research 57, 305-312. DOI: 10.1007/s10344-010-0429-2.

Bray, Y., Devillard, S., Marboutin, E., Mauvy, B. \& Peroux, R. (2007). Natal dispersal of European hare in France. Journal of Zoology 273, pp. 426-434. DOI: 10.1111/j.14697998.2007.00348.x.

Caley, P.A. \& Morley, C.G. (2002). Assessing growth rates of European rabbit populations using spotlight transect counts. Journal of Wildlife Management 66, pp. 131-137. DOI: 10.1071/WR02014.

Calvete, C., Estrada, R. Angulo, E. \& Cabezas-Ruiz, S. (2004). Habitat factors related to wild rabbit conservation in an agricultural landscape. Landscape Ecology 19, pp. 531-542. DOI: 10.1023/B:LAND.0000036139.04466.06. 
Cardarelli, E., Meriggi, A., Brangi, A. \& Vidus-Rosin, A. (2011). Effects of arboriculture stands on European hare (Lepus europaeus) spring habitat use in an agricultural area of northern Italy. Acta Theriologica 56, pp 229-238. DOI: 10.1007/s13364-010-0019-4.

Caruso, S. \& Siracusa, A.M. (2001). Factors affecting the abundance of wild rabbit (Oryctolagus cuniculus) in agro-ecosystems of the Mount Etna Park. Hystrix Italian Journal of Mammalogy 12, pp. 45-49. DOI: 10.4404/hystrix-12.1-4170.

Carvalho, J.C. \& Gomes, P. (2003). Habitat suitability model for European wild rabbit (Oryctolagus cuniculus) with implications for restocking. Game and Wildlife Science 20, pp. 287-301.

Carvalho, J.C. \& Gomes, P. (2004). Influence of herbaceous cover, shelter and land cover structure on wild rabbit abundance in NW Portugal. Acta Theriologica 49, pp. 63-74.DOI: 10.1007/BF03192509.

Catalán, I., Rodríguez-Hidalgo, P. \& Tortosa, F.S. (2008). Is habitat management an effective tool for wild rabbit (Oryctolagus cuniculus) population reinforcement? European Journal of Wildlife Research 54, pp. 449-453. DOI: 10.1007/s10344-007-0169-0.

Catling, P.C. \& Burt, R.J. (1995). Studies of the ground-dwelling mammals of Eucalypt Forests in south-eastern New South Wales: the effect of environmental variables on distribution and abundance. Wildlife Research 22, pp. 669-685. DOI: 10.1071/WR9950669.

Dahl, F. (2005). Distinct seasonal habitat selection by annually sedentary mountain hares (Lepus timidus) in the boreal forest of Sweden. European Journal of Wildlife Research 51, pp. 163-169. DOI: 10.1007/s10344-005-0095-y.

Delibes-Mateos, M., Delibes, M., Ferreras, P. \& Villafuerte, R. (2008). Key Role of European Rabbits in the Conservation of the Western Mediterranean Basin Hotspot. Conservation Biology 22, pp. 1106-1117. DOI: 10.1111/j.1523-1739.2008.00993.x.

Delibes-Mateos, M., Ferreras, P. \& Villafuerte, R. (2009). Rabbit (Oryctolagus cuniculus) abundance and protected areas in central-southern Spain: why they do not match? European Journal of Wildlife Research 55, pp. 65-69. DOI: 10.1007/s10344-008-0216-5.

Delibes-Mateos, M., Farfán, M.A., Olivero, J. \& Vargas, J.M. (2010). Land-use changes as a critical factor for long-term wild rabbit conservation in the Iberian Peninsula. Environmental Conservation 37, pp. 1-8. DOI: 10.1017/S0376892910000214.

Dellafiore, C.M., Gallego Fernández, J.B. \& Muñoz Vallés, S. (2010). The rabbit (Oryctolagus cuniculus) as a seed disperser in a coastal dune system. Plant Ecology 206, pp. 251-261. DOI: 10.1007/s11258-009-9639-7.

DeStefano, S. (2002). Regional and national issues for forest wildlife research and management. Forest Science 48, pp. 181-189.

Devillard, S., Aubineau, J., Berger, F., Léonard, Y., Roobrouck, A. \& Marchandeau, S. (2008). Home range of the European rabbit (Oryctolagus cuniculus) in three contrasting French populations. Mammalian Biology 73, pp. 128-137. DOI: 10.1016/j.mambio.2007. 01.003 .

Eberhardt, L., Peterle, T.J. \& Schofield, R. (1963). Problems in a rabbit population study. Wildlife Monographs 10, pp. 3-51.

Eldridge, D.J. \& Simpson, R. (2002). Rabbit (Oryctolagus cuniculus L.) impacts on vegetation and soils, and implications for management of wooded rangelands. Basic and Applied Ecology 3, pp. 19-29. DOI: 10.1078/1439-1791-00078. 
Estanoba, A., Solís, A., Iriondo, M., Sanz-Martín, M.J., Pérez-Suárez, G., Markov, G. \& Palacios, F. (2006). The genetic distinctiveness of the three Iberian hare species: Lepus europaeus, L. granatensis, and L. castroviejoi. Mammalian Biology 71, pp. 52-59. DOI: 10.1016/j.mambio.2005.08.010.

Farfan, M.A., Vargas, J.M., Guerrero, J.C., Barbosa, A.M., Duarte, J. \& Real, R. (2008). Distribution modeling of wild rabbit hunting yields in its orginal area (S Iberian Peninsula). Italian Journal of Zoology 75, pp. 161-172. DOI: 10.1080/11250000701868717.

Fernandez, N. (2005). Spatial patterns in European rabbit abundance after a population collapse. Landscape Ecology 20, pp. 897-910. DOI: 10.1007/s10980-004-3976-7.

Fernandez-de-Simon, J., Diaz-Ruiz, F., Cirilli, F., Tortosa, F.S., Villafuerte, R., DelibesMateos, M. \& Ferreras, P. (2011). Towards a standardized index of European rabbit abundance in Iberian Mediterranean habitats. European Journal of Wildlife Research 57, pp. 1091-1100. DOI: 10.1007/s10344-011-0524-z.

Ferreira, C. \& Alves, P.C. (2009). Influence of habitat management on the abundance and diet of the wild rabbit (Oryctolagus cuniculus algirus) populations in Mediterranean ecosystems. European Journal of Wildlife Research 55, pp. 487-496. 10.1007/s10344-0090257-4.

Fisher, C. \& Tagand, R. (2012). Spatial behaviour and survival of translocated wild brown hares. Animal Biodiversity and Conservation 35, pp. 189-196.

Fulgione, D., Maselli, Pavarese, G., Rippa, D. \& Rastogi, R.K. (2009). Landscape fragmentation and habitat suitability in endangered Italian hare (Lepus corsicanus) and European hare (Lepus europaeus) populations. European Journal of Wildlife Research 55, pp. 385-396. DOI: 10.1007/s10344-009-0256-5.

Gea-Izquierdo, G., Muñoz-Igualada, J. \& San Miguel-Ayanz, A. (2005). Rabbit warren distribution in relation to pasture communities in Mediterranean habitats: consequences for management of rabbit populations. Wildlife Research 32, pp. 723-731. DOI: 10.1071/ WR04129.

Genini Gamboni, A-S., Bisi, F., Masseroni, E., Nodari, M., Preatoni, D.G., Wauters, L.A., Martinoli, A. \& Tosi, G. Home range dynamics of mountain hares (Lepus timidus) in the Swiss Alps. Hystrix Italian Journal of Mammalogy 19, pp. 157-163. DOI: 10.4404/hystrix19.2-4425.

Gortazar, C., Millán, J., Acevedo, P., Escudero, M.A., Marco, J. \& Fernández de Luco, D. (2007). A large-scale survey of brown hare Lepus europaeus and Iberian hare $L$. granatensis populations at the limit of their ranges. Wildlife Biology 13, pp. 244-250. DOI: 10.2981/0909-6396(2007)13[244:ALSOBH]2.0.CO;2.

Hill, D., Fasham, M., Tucker, G., Shewry, M. \& Shaw, P. (2005). Handbook of Biodiversity Methods: Survey, Evaluation, and Monitoring. New York: Cambridge University Press.

Jansson, G. \& Pherson, A. (2007). The recent expansion of the brown hare (Lepus europaeus) in Sweden with possible implications to the mountain hare (L. timidus). European Journal of Wildlife Research 53, pp. 125-130. DOI: 10.1007/s10344-007-0086-2.

Johnson, D.H. (2002). The importance of replication in wildlife research. Journal of Wildlife Management 66, pp. 919-932.

Jongman, R.H.G. (2002). Homogenisation and fragmentation of the European landscape: ecological consequences and solutions. Landscape and Urban Planning 58, pp. 211-221. DOI: 10.1016/S0169-2046(01)00222-5. 
Leitão, A.B. \& Ahern, J. (2002). Applying landscape ecological concepts and metrics in sustainable landscape planning. Landscape and Urban Planning 59, pp. 65-93. DOI: 10.1016/S0169-2046(02)00005-1

Letty, J., Aubineau, J., Marchandeau, S. \& Colbert, J. (2003). Effect of translocation on survival in wild rabbit (Oryctolagus cuniculus). Mammalian Biology 68, pp. 250-255. DOI: 10.1078/1616-5047-00092.

Letty, J., Aubineau, J. \& Marchadneau, S. (2005). Effect of storage conditions on dispersal and short-term survival of translocated wild rabbits Oryctolagus cuniculus. Wildlife Biology 11, pp. 249-255. DOI: 10.2981/0909-6396(2005)11[249:EOSCOD]2.0.CO;2.

Lindenmayer, D. et al. (2008). A checklist for ecological management of landscapes for conservation. Ecology Letters 11, pp. 78-91. DOI: 10.1111/j.1461-0248.2007.01114.X

Lombardi, L., Fernandez, N., Moreno, S. \& Villafuerte, R. (2003). Habitat-related differences in rabbit (Oryctolagus cuniculus) abundance, distribution, and activity. Journal of Mammalogy 84, pp. 26-36. DOI: 10.1644/1545-1542(2003)084<0026:HRDIRO> 2.0.CO;2.

Lundström-Gilliéron, C. \& Schlaepfer, R. (2003). Hare abundance as an indicator for urbanization and intensification of agriculture in Western Europe. Ecological Modelling 168, pp. 283-301. DOI: 10.1016/S0304-3800(03)00142-X.

Marboutin, E., Bray, Y., Péroux, B., Mauvy, B. \& Lartiges, A. (2003). Population dynamics in European hare: breeding parameters and sustainable harvest rates. Journal of Applied Ecology 40, pp. 580-591. DOI: 10.1046/j.1365-2664.2003.00813.x.

Marchandeau, S., Aubineau, J., Berger, F., Gaudin, J.C., Roobrouck, A., Corda, E. \& Reitz, F. (2006). Abundance indices: reliability testing is crucial - a field case of wild rabbit Oryctolagus cuniculus. Wildlife Biology 12, pp. 19-27. DOI: 10.2981/0909-6396(2006)12 [19:AIRTIC]2.0.CO;2.

Martín-López, B., Mones, C., Ramírez, L. \& Benayas, J. (2009). What drives policy decision-making related to species conservation? Biological Conservation 142, pp. 13701380. DOI: 10.1016/j.biocon.2009.01.030.

Monzón, A., Fernandes, P. \& Rodrigues, N. (2004). Vegetation structure descriptors regulating the presence of wild rabbit in the National Park of Peneda-Geres, Portugal. European Journal of Wildlife Research 50, pp. 1-6. DOI: 10.1007/s10344-003-0027-7.

Navarro-Gonzalez, N., Serrano, E., Casas-Díaz, E., Velarde, R., Marco, I., Rossi, L. \& Lavín, S. (2010). Game restocking and the introduction of sarcoptic mange in wild rabbit in north-eastern Spain. Animal Conservation 13, pp. 586-591. DOI 10.1111/j.14691795.2010.00390.x.

Nodari, M., Masseroni, E., Preatoni, D.C., Wauters, L.A., Tosi, G. \& Martionoli, A. (2005). Live-trapping success of the mountain hare (Lepus timidus) in the Southern Italian Alps. Hystrix Italian Journal of Mammalogy 16, pp. 143-148. DOI: 10.4404/hystrix-16.2-4352.

Noss, R.F. (1990). Indicators for monitoring biodiversity: a hierarchical approach. Conservation Biology 4, pp. 355-364. DOI: 10.1111/j.1523-1739.1990.tb00309.x.

Palomares, F. (2001). Comparison of 3 methods to estimate rabbit abundance in a Mediterranean environment. Wildlife Society Bulletin 29, pp. 578-585.

Pépin, D. \& Angibault, J.M. (2007). Selection of resting sites by the European hare as related to habitat characteristics during agricultural changes. European Journal of Wildlife Research 53, pp. 183-189. DOI: 10.1007/s10344-007-0087-1. 
Petrovan, S.O., Barrio, I.C., Ward, A.I. \& Wheeler, P.M. (2011). Farming for pests? Local and landscape-scale effects of grassland management on rabbit densities. European Journal of Wildlife Research 57, pp. 27-34. DOI: 10.1007/s10344-010-0394-9.

Reger, B., Otte, A. \& Waldhardt, R. (2007). Identifying patterns of land-cover change and their physical attributes in a marginal European landscape. Landscape and Urban Planning 81, pp. 104-113. DOI:10.1016/j.landurbplan.2006.10.018.

Reger, B., Sheridan, P., Simmering, D., Otte, A. \& Waldhardt, R. (2009). Potential effects of direct transfer payments on farmland habitat diversity in a marginal European landscape. Environmental Management 43, pp. 1026-1038. DOI: 10.1007/s00267-008-9270-8.

Reynolds, J.C., Stoate, C., Brockless, M.H., Aebischer, N.J. \& Tapper, S.C. (2010). The consequences of predator control for brown hares (Lepus europaeus) on UK farmland. European Journal of Wildlife Research 56, pp. 541-549. DOI: 10.1007/s10344-009-0355-3.

Roedenbeck, I.A. \& Voser, P. (2008). Effects of roads on spatial distribution, abundance and mortality of brown hare (Lepus europaeus) in Switzerland. European Journal of Wildlife Research 54, pp. 425-437. DOI: 10.1007/s10344-007-0166-3.

Rosenzweig, M.L. (1991). Habitat selection and population interactions: the search for mechanism. The American Naturalist 137, pp. 5-28. DOI:10.1086/285137.

Rueda, M., Rebollo, S. \& Galvez Bravo, L. (2008). Age and season determine European rabbit habitat use in Mediterranean ecosystems. Acta Oecologica 34, pp. 266-273. DOI: 10.1016/j.actao.2008.03.007.

Rühe, F. \& Hohmann, U. (2004). Seasonal locomotion and home-range characteristics of European hares (Lepus europaeus) in an arable region in central Germany. European Journal of Wildlife Research 50, pp. 101-111. DOI: 10.1007/s10344-004-0049-9.

Santilli, F. \& Bagliacca, M. (2010). Habitat use by the European wild rabbit (Oryctolagus cuniculus) in a coastal sandy dune ecosystem of central Italy. Hystrix Italian Journal of Mammalogy 21, pp. 57-64. DOI: 10.4404/hystrix-21.1-4486.

Schmidt, P.M., McCleery, R.A., Lopez, R.R., Silvy, N.J., Schmidt, J.A. \& Perry, N.D. (2011). Influence of patch, habitat, and landscape characteristics on patterns of Lower Key marsh rabbit occurrence following Hurricane Wilma. Landscape Ecology 26, pp. 14191431. DOI: 10.1007/s10980-011-9654-7.

Serrano Pérez, S., Jacksic, D., Meriggi, A. \& Vidus Rosin, A. (2008). Density and habitat use by the European wild rabbit (Oryctolagus cuniculus) in an agricultural area of northern Italy. Hystrix Italian Journal of Mammalogy 19, pp. 143-156. DOI: 10.4404/hystrix-19.24424.

Smith, R.K., Jennings, N.V., Tataruch, F., Hackländer, K. \& Harris, S. (2005). Vegetation quality and habitat selection by European hares Lepus europaeus in a pastural landscape. Acta Theriologica 50, pp. 391-404. DOI: 10.1007/BF03192634.

Smith, R.K., Jennings, N.V., Robinson, A. \& Harris, S. (2004). Conservation of European hares Lepus europaeus in Britain: is increasing habitat heterogeneity in farmland the answer? Journal of Applied Ecology 41, pp. 1092-1102. DOI: 10.1111/j.00218901.2004.00976.x.

Vidus-Rosin, A., Meriggi, A., Cardarelli, E., Serrano-Perez, S., Mariani, M-C., Corradelli, C. \& Barba, A. (2011). Habitat overlap between sympatric European hares (Lepus europaeus) and Eastern cottontails (Sylvilagus floridanus) in northern Italy. Acta Theriologica 56, pp. 53-61. DOI: 10.1007/s13364-010-0005-x. 
Virgós, E., Cabezas-Díaz, S., Malo, A., Lozano, J. \& López-Huertas, D. (2003). Factors shaping European rabbit abundance in continuous and fragmented populations of central Spain. Acta Theriologica 48, pp. 113-122. DOI: 10.1007/BF03194271.

Williams, D., Acevedo, P., Gortazar, C., Escudero, M.A., Labarta, J.L., Marco, J. \& Villafuerta, R. (2007). Hunting for answers: rabbit (Oryctolagus cuniculus) population trends in northeastern Spain. European Journal of Wildlife Research 53, pp. 19-28. DOI: 10.1007/s10344-006-0056-0.

Willis, K.J., Araújo, M.B., Bennett, K.D., Figueroa-Rangel, B., Froyd, C.A. \& Myers, N. (2007). How can knowledge of the past help to conserve the future? Biodiversity conservation and the relevance of long-term ecological studies. Phil Trans Royal Society B 362, pp. 175-187. DOI:10.1098/rstb.2006.1977.

Zedler, P.H. \& Black, C. (1992). Seed dispersal by a generalized herbivore: rabbits as dispersal vectors in a semiarid California Vernal Pool landscape. American Midland Naturalist 128, pp. 1-10. DOI: 10.2307/2426407.

Zellweger-Fischer, J., Kery, M. \& Pasinelli, G. (2011). Population trends of brown hares in Switzerland: the role of land-use and ecological compensation areas. Biological Conservation 144, pp. 1364-1373. DOI:10.1016/j.biocon2010.11.021.

Zollner, P.A., Smith, W.P. \& Brennan, L.A. (1996). Characteristics and adaptive significance of latrines of swamp rabbits (Sylvilagus aquaticus). Journal of Mammalogy 77, pp. 1049-1058. DOI: $10.2307 / 1382785$. 